\title{
Production of fermented fruit juice and value addition by blending medicinal plants
}

\begin{abstract}
Fermented fruit juice is beverage typically made of controlled fermentation of fruits. The fruits used in the study were Wild Grapes, Guava, Sapota, Fig, Pomegranate, Kokum, and blends of Guava with Kokum and Sapota with medicinal plants Ginger (Zingiber officinale), Tulsi (Ocimum tenuiflorum), Amrutha balli (Tinospora cordifoli) and Dodda pathre (Coleus aromaticus). The musts of the fruits were extracted, pasteurized and subjected to anaerobic fermentation by inoculating with yeast with an initial $\mathrm{pH}$ of 3.5 and initial sugar concentration of $20-22^{\circ} \mathrm{Brix}$ at $28^{\circ} \mathrm{C} \pm 2^{\circ} \mathrm{C}$. Then fermented fruit juice was subjected to malolactic fermentation using Oenococcus oeni. The residual concentration of all the samples was found to be less than $1 \mathrm{~g} / \mathrm{L}$, fixed acidity in terms of tartaric acid equivalent was found to be in the range of $13.93 \mathrm{~g} / \mathrm{L}$ to $3.31 \mathrm{~g} / \mathrm{L}$, radical scavenging activity in terms of ascorbic acid equivalent was found to be in the range $0.15-0.5 \mathrm{mg} / \mathrm{mL}$, percentage of ethanol was found to be in the range of $9.1-10.1 \%(\mathrm{v} / \mathrm{v})$.
\end{abstract}

Keywords: fermented fruit juice, acidity, residual sugar, ethanol

\author{
Volume 5 Issue 6 - 2017
}

\author{
Vinayaka B Shet,' Sagar SD,' Bollamma MN,' \\ Mary Teena J,' Vaman Rao C,' Aparna A, ${ }^{2}$ \\ Silvia Yumnam ${ }^{3}$ \\ 'Department of Biotechnology Engineering, nmAM Institute of \\ Technology, India \\ ${ }^{2}$ Department of Microbiology and Molecular Genetics, Hebrew \\ University of Jerusalem, Israel \\ ${ }^{3}$ College of Pharmacy, Gachon University, Republic of Korea
}

Correspondence: Vinayaka B Shet, nmAM institute of technology (V.T.U, Belagavi), Nitte, Karkala, Karnataka, India, Tel +918258281263, Email vinayakabshet@nitte.edu.in

Received: October 26, 2017 | Published: November 22, 2017

\section{Introduction}

Fermented fruit juice is a popular drink being enjoyed all over the world. Historians believe that fermented fruit juice was being made in Caucasus and Mesopotamia as early as 6000 BC. Rig-Veda amply testifies that the fermented fruit juice is perhaps the oldest fermented product known to man. It has been made in India for as many as 5,000 years. In developing countries like India $20-30 \%$ of fruits produced are wasted due to lack of proper utilization, postharvest and processing technology. By converting the waste into value added products like fermented fruit juice is a smart solution for this problem. ${ }^{1}$ Any fruit with good proportion of sugar may be used in producing fermented fruit juice and the resultant fruit juice is normally named after the fruit. The type of fermented fruit juice to be produced dictates the fruit and strain of yeast to be involved. Preservatives used in fermented fruit juice making include sulphurdioxide potassium sorbate, sorbic acid and metabisulphites.

Fermented fruit juice is one of the functional fermented foods and has many health benefits. Epidemiological evidence has been provided showing that constituents in fruits are beneficial to human health and contribute to the prevention of degenerative processes caused by oxidative stress. ${ }^{2}$ Fruits contain many different dietary phytonutrients with strong antioxidant capacities; such as: phenolics, which include flavonoids and phenolic acids; carotenoids; and vitamins. Dietary intake of plant phenolics are inversely related to coronary heart disease and act as anti-ulcer, antispasmodic, anti-secretory, or antidiarrheal agents in the gastrointestinal tract. Certain flavonoids have been shown to inhibit the activity of free radical generating enzymes aldose reductase, which cause diabetic cataracts and tumour growth in modelled systems. The concentration of someminerals in fermented fruit juice is important due to health impact ofminerals, their role in the stability of fermented fruit juice, possibility of toxicological risks and food regulations. Themineral profile of fermented fruit juices has also been proposed as a possible fingerprint that could be used to characterize fermented fruit juices based on their geographical origin. ${ }^{3}$

Fruits like guava and pomegranate are easy to culture, possess high nutritive value and its products like juices, beverages nectars, etc. are largely appreciated by the consumers. Average energy contribution to total energy intake is estimated to be $10-20 \%$ among adults. These fruits are difficult to keep for long and are utilized either as fresh or processed juice and specialty products. In general fruit fermented fruit juices are processed in the same way as wine made from grapes and significant compositional changes take part during wine making. Likewise phenolic compounds are not only health promoting bioactivities but also greatly contribute to the sensory properties of stuff by alternating colour taste. ${ }^{4}$ Fruit juices contain water and $20 \%$ carbohydrates, $1 \%$ organic acids and trace amounts of vitamins, minerals and nitrogenous compounds. The sugars, organic acids and phenolics give the juice its flavour, while the vitamins, minerals and nitrogenous compounds are, in many cases, essential to yeast growth and fermentation. Fermented fruit juice has a similar composition, but has much lower levels of sugar (none in dry wines), 8-13\% alcohol and a greater range of minor components..$^{5}$ In the current investigation an attempt was made to blend unconventional fruits with medicinal plants to produce fermented fruit juice.

\section{Materials and methods}

\section{Preparation of mash}

Fruits were collected from local market of Karkala situated in Udupi district of Karnataka state, India. Fruits were washed with water and further with $50 \mathrm{ppm}$ potassium metabisulfite solution. To prepare the mash, fruits were crushed using mortar and pestle. The mash along with the seeds and the rind was pasteurized at $70-80^{\circ} \mathrm{C}$ for 15 minutes. After pasteurization, filtration was carried out using strainers and $500 \mathrm{ml}$ of the filtrate was collected. ${ }^{6}$

\section{Blending medicinal plants}

Medicinal plants such as Ginger (Zingiber officinale), Tulsi (Ocimum tenuiflorum), Amrutha balli (Tinospora cordifoli) and Dodda pathre (Coleus aromaticus) $)^{7,8}$ were collected from then mAMIT campus situated in Nitte village. These plant materials were washed thoroughly with tap water. To incorporate medicinal value, plant materials were boiled for $10 \mathrm{~min}$ and extract was cooled to 
room temperature. Further plant extract along with plant materials blended with mash (Table 1). Initial sugar was determined by using a hydrometer in terms of ${ }^{\circ}$ Brix. Final sugar concentration was adjusted to $20-22^{\circ} \mathrm{Brix}$. To bring the sugar concentration to the required value, chaptalization was carried out by adding table sugar. ${ }^{4}$ The $\mathrm{pH}$ was adjusted to 3.5 by adding tartarate crystals. ${ }^{9}$

Table I Sample composition

\begin{tabular}{ll}
\hline Name & Sample components \\
\hline FI & Wild grapes I \\
F2 & Wild grapes2 \\
F3 & Guava \\
F4 & Sapota \\
F5 & Kokum+Guava \\
F6 & Pomegranate \\
F7 & Fig \\
F8 & Sapota+Ginger \\
F9 & Sapota+Tulsi \\
FI0 & Sapota+Dodda pathre \\
FII & Sapota+Amrutha balli \\
\hline
\end{tabular}

\section{Inoculum preparation and anaerobic fermentation}

Inoculum preparation: Freeze dried Saccharomyces cerevisiae was rehydrated by transferring $1 \mathrm{~g}$ of yeast into $10 \mathrm{~mL}$ of water and incubated for $15 \mathrm{~min}$ at $28^{\circ} \mathrm{C} \pm 2^{\circ} \mathrm{C}$. To the rehydrated Saccharomyces cerevisiae few drops of mash was transferred and further incubated for $10 \mathrm{~min}$ at $28^{\circ} \mathrm{C} \pm 2^{\circ} \mathrm{C}$. As the effervescence started generating, Erlenmeyer flask containing mash was pitched in with inoculum.

Anaerobic fermentation: To maintain the anaerobic condition, airlock was used. U-shaped airlock made up glass was half filled with water to prevent the entry of oxygen and to facilitate release of carbon dioxide liberated during anaerobic fermentation. Centrally bored cork having airlock was fitted to conical flask. To avoid growth of microorganism in the airlock, Potassium metabisulphite was added to the water present in the airlock. Fermentation was carried out at $28^{\circ} \mathrm{C} \pm 2{ }^{\circ} \mathrm{C}$.

\section{Malolactic fermentation}

The culture of Oenococcus oeni was procured from NCIM, Pune, India. To each of the fermented fruit juice samples, $0.1 \mathrm{~mL}$ of the culture was inoculated and malolactic fermentation was carried out for 7 days.

\section{Analytical methods}

Initial sugar concentration in terms of Brix was determined using hydrometer. The residual sugar concentration was estimated on daily basis using the spectrophotometric method using the UV Vis spectrophotometer at $540 \mathrm{~nm}$ with 3,5 - DNSA reagent. ${ }^{10}$ Titratable acidity of the fermented fruit juice was determined by titration method of a strong base against sample to an end point of $\mathrm{pH} 8.2$ using potentiometric titration. ${ }^{11}$ Volatile acidity of samples was determined by distillation of fermented fruit juice and the distillate was titrated against $\mathrm{NaOH}$ using phenolphthalein as indicator to determine volatile acid content. ${ }^{12}$ The radical scavenging activity of fermented fruit juice samples were analysed by the 2, 2-diphenylpicrylhydrazyl (DPPH) method..$^{13}$ The percentage of ethanol present in the fermented fruit juice samples was estimated using GC (Shimadzu GC-2014).

\section{Results and discussion}

\section{Estimation of initial sugar concentration}

Initial sugar concentration plays major role in fermentation and ethanol concentration. Soon after crushing fruits estimation of initial sugar concentration was done using a hydrometer. Then concentration was adjusted to 18 Brix by capitalization. The initial sugar concentration (0Brix) was found to be highest in Chickoo (15.20Brix) and lowest in guava (1.30Brix). The sugar concentrations were made up to approximately 20-220Brix by chaptalization. ${ }^{14}$

\section{Estimation of residual sugar}

The residual concentration of all the samples was found to be less than $1 \mathrm{~g} / \mathrm{L}$ or $0.110 \mathrm{Brix}$ and there is no chance of contamination at the time of storing fermented fruit juice, hence the longer shelf life.

\section{Estimation of acidity}

Amount of acetic acid present in fermented fruit juice is expressed as volatile acidity. The result reveals the presence of acetic acid in the fermented fruit juice.

Titratable acidity is determined using following equation.

Titratable acidity $(\mathrm{g} / \mathrm{L})=75 \times \mathrm{N} \times(\mathrm{T} / \mathrm{S})$

Where $\mathrm{N}$ is the normality of $\mathrm{NaOH}, \mathrm{T}$ is the titer volume (inmL), $\mathrm{S}$ is the sample volume (inmL) and 75 is a constant.

Fixed acidity $=$ Titratable acidity - Volatile acidity

As per the Organisation of Vine and Wine (OIV) norms fixed acidity should not be less than $5 \mathrm{~g} / \mathrm{L}$.

The fixed acidity in terms of tartaric acid equivalent was found to be highest in pomegranate $(5.87 \mathrm{~g} / \mathrm{L})$ and lowest in sapota with ginger $(3.31 \mathrm{~g} / \mathrm{L})$.

\section{Radical scavenging activity}

The radical scavenging activity of the fermented fruit juice samples was calculated using DPPH assay and was found to be as follows in terms of ascorbic acid equivalent. The radical scavenging activity for all the samples in terms of ascorbic acid equivalent was found to be in the range $0.08-0.49 \mathrm{~g} / \mathrm{L}$.

\section{Ethanol estimation}

The percentage of ethanol present in the fermented fruit juice samples was estimated using gas chromatography. The percentage of alcohol for all the fermented fruit juice samples was found to be in the range of $9.0-10.5 \%$. The highest ethanol content is present in pomegranate.

\section{Conclusion}

The current research work has revealed the possibility of blending medicinal plants with fruit juice for value addition. After analysing the fermented fruit juice that was produced from different fruits and blending combination it was found that the residual sugar concentration was less than $1 \mathrm{~g} / \mathrm{L}$. The fixed acidity was maximum in Guava fermented fruit juice $5.87 \mathrm{~g} / \mathrm{L}$, Wild grapes showed the 
maximum radical scavenging activity, $0.49 \mathrm{~g} / \mathrm{L}$ and the maximum ethanol content of $10 . \%(\mathrm{v} / \mathrm{v})$ was found in pomegranate. Quality of the fermented fruit juice can be improved further to match market requirement.

\section{Acknowledgements}

None.

\section{Conflict of interest}

The authors declare that they have no conflict of interest.

\section{References}

1. Reddy LV, Sudheer Kumar Y, Reddy OV. Production and Characterization of Wine from Mango Fruit (Mangifera indica L). Indian J Microbiol. 2005;50(2):183-191.

2. Bansal N, Soni R, Soni SK. Standardization of conditions for fermentation and maturation of wine from Amla (Emblica officinalis Gaertn). Nat Prod Rad. 2009;8(4):436-444.

3. Edwards GC, Beelman RB. Inducing malolactic fermentation in wine. Biotechnology advances. 2002;7(3):336-360.

4. Gurvinder SK, Pooja. Status of wine production from guava (Psidium guajava L.): A traditional fruit of India. Afr J Food Sci. 2011;5(16):851860 .

5. Mena P, Vilaplana AG, Martí N, et al. Pomegranate varietal wines: Phytochemical composition and quality parameters. Food Chem. 2012;133(1):108-115.
6. Ganjyal GM, Hanna NA, Devadattam DSK. Processing of sapota. $J$ Food Technol. 2005;3(3):326-330.

7. Shipra B, Kshipra D, Amla B, et al. Zingiber Officinale: Chemical and phytochemical screening and evaluation of its antimicrobial activities. $J$ Chem Pharm Res. 2012;4(1):360-364.

8. Subir KD, Vasudevan DM. Tulsi the Indian Holy Power plant. Nat Prod Rad. 2005;5(4):279-283.

9. Oliveira MES, Pantoja L, Duarte WF, et al. Fruit wine produced from cagaita (Eugenia dysenterica DC) by both free and immomibilised yeast cell fermentation. Food Res Int. 2011;44(7):2391-2400.

10. Miller GL. Use of dinitrosalicylic acid reagent for determination of reducing sugar. Anal Chem. 1959;31(3):426-428.

11. Jean LJ. Introduction to wine laboratory practices and procedures. 1st ed. USA: Springer Science Business Media Inc; 2006.

12. Vilela-Moura A, Schuller D, Falco V, et al. Effect of refermentation conditions and micro-oxygenation on the reduction of volatile acidity by commercial S. cerevisiae strains and their impact on the aromatic profile of wines. Int J Food Microbiol. 2010;141(3):165-172.

13. Marijan S, Ivana N, Lidija J. Determination of polyphenols content and antioxidant activity of some red wines by differential pulse voltammetry, HPLC and spectrophotometric methods. Food Chem. 2011;124(3):12081216.

14. Kocher GS. Status of wine production from guava (Psidium guajava L.):A traditional fruit of India. Afr J Food Sci African Journal of Food Science. 2011;5(16):851-860. 